\title{
A retrospective cross sectional analysis of histopathological distribution of breast cancer according to age at a tertiary care teaching hospital
}

\author{
Anand Nagalikar ${ }^{1}$, Rashmi Chandragouda Meti ${ }^{2 *}$ \\ ${ }^{\mathbf{1}}$ Associate Professor, Dept. of Pathology, ESIC Medical College, Gulburga, Karnataka, ${ }^{2}$ Associate Professor, Dept. of \\ Microbiology, Kamineni Institute of Medical Sciences, Nalgonda, Telangana, India \\ *Corresponding Author: Rashmi Chandragouda Meti \\ Email: anagalikar@gmail.com
}

Received: $5^{\text {th }}$ April, 2018

Accepted: $27^{\text {th }}$ April, 2018

\begin{abstract}
Introduction: As per the WHO, there were 519,000 women who died in the year 2004 and $69 \%$ of the world's cancer deaths are due to breast cancer. The present study was conducted with the aim to determine the histological variants of breast cancer amongst females reposting to the hospital.

Materials and Methods: The present descriptive study was conducted in retrospective fashion in the Department of Pathology, ESIC Medical College, Gulburga, Karnataka (India). All the data was obtained from the hospital's medical records and the identity of the subjects was kept confidential. A complete family history, medical history and clinical examination of the subjects were recorded. Details of the site of histology sample and the histopathological variant were recorded. The usual technique for fixing the specimen in formalin followed by embedding in paraffin and cutting with $\mathrm{H}$ and $\mathrm{E}$ staining was followed for all the samples. All the data obtained was arranged in a tabulated form and analyzed using SPSS software. The results were expressed as frequency distribution.

Results: Majority of the cases occurred between 32-46 years of age followed by 62-76 years. There were only 3 cases diagnosed between 0-15 years age group. There were $93 \%$ cases of carcinomas. Out of these, majority ( $\mathrm{n}=317$ ) were infiltrating ductal carcinomas. In 210 cases, infiltrating lobular carcinomas were confirmed histologically.

Conclusion: Breast cancer is the most frequently seen cancer amongst women. It is most commonly seen in elder age groups and hereditary plays an important role in its causation. The most commonly seen histological variant of breast cancer is infiltrative ductal carcinoma. Sarcomas are the second most common variant of breast cancer.
\end{abstract}

Keywords: Breast, Carcinoma, Histology.

\section{Introduction}

Breast cancer is the most frequently seen cancer amongst women around the world and it represents around $16 \%$ of the female cancers. As per the WHO, there were 519,000 women who died in the year 2004 and $69 \%$ of the world's cancer deaths are due to breast cancer. ${ }^{1}$ It is associated with various risk factors. The risk factors not only involve genetic, environmental and demographic factors but also hormonal, lifestyle and dietary habits. Clinical manifestations include lump in breast, discharge from nipple and involvement of axillary lymph nodes in advance cases. Screening of the cases using imaging modalities and biopsy allows earlier diagnosis and better prognosis of the lesion. ${ }^{2}$ In case of developing countries, this screening is poor and hence the rates are increasing at a steady rate and breast cancer is becoming a public health problem. The prognosis in most countries is poor because of lack of appropriate management strategies in most counties. ${ }^{1}$ Around $15 \%$ of breast cancers occur in women with a history of disease amongst first-degree relations ${ }^{3}$, and around $5-10 \%$ of breast cancers are directly linked to heredity. ${ }^{4,5}$ In a study conducted by Diomandé et al, the most commonly seen cancer amongst women was cervical cancer followed by breast cancer seen in $10.52 \%$ of the subjects. ${ }^{6}$ According to another study conducted by Echimane et al every 24.5 cases per
100,000 are of breast cancer. ${ }^{7}$ The present study was conducted with the aim to determine the histological variants of breast cancer amongst females reposting to the hospital.

\section{Materials and Methods}

The present descriptive study was conducted in retrospective fashion in the Department of Pathology, ESIC Medical College, Gulburga, Karnataka (India). All the subjects with breast cancer operated in the hospital were included in the study. The study was approved by the institute's ethical board. All the data was obtained from the hospital's medical records and the identity of the subjects was kept confidential. A complete family history, medical history and clinical examination of the subjects were recorded. Details of the site of histology sample and the histopathological variant were recorded. The usual technique for fixing the specimen in formalin followed by embedding in paraffin and cutting with $\mathrm{H}$ and $\mathrm{E}$ staining was followed for all the samples. Most of the subjects underwent partial or total mastectomy with or without removal of axillary lymph nodes. All the data obtained was arranged in a tabulated form and analyzed using SPSS software. The results were expressed as frequency distribution. 


\section{Results}

The study enrolled a total of 600 subjects with a mean age of $46.62+/-9.75$ years. In all the subjects diagnosis of breast cancer was confirmed.

Table 1 illustrates the age distribution of the subjects. Majority of the cases occurred between 32-46 years of age followed by 62-76 years. There were only 3 cases diagnosed between $0-15$ years age group. There were 118 cases between 16-31 years of age. 224 cases were diagnosed between 32-46 years of age. There were 110 cases and 145 cases diagnosed between 47-61 and 62-76 years of age respectively.

Table 2 demonstrates the histological variation of breast cancer. There were $93 \%$ cases of carcinomas. Out of these, majority $(n=317)$ were infiltrating ductal carcinomas. In 210 cases, infiltrating lobular carcinomas were confirmed histologically. There were only 4 cases of adenoid cystic carcinoma. In 15 cases medullary carcinomas were confirmed histologically. There were 6 cases each of ductal carcinoma in situ and lobular carcinoma in situ. In $5.1 \% \quad(n=31)$ sarcomas were confirmed histologically. Out of theses majority $(n=16)$ occurred between 32-46 years of age. There was only 1 case of paget's disease in our study occurring between 32-46 years of age. In 1.6\% ( $\mathrm{n}=10)$ cases lymphomas were confirmed histologically.

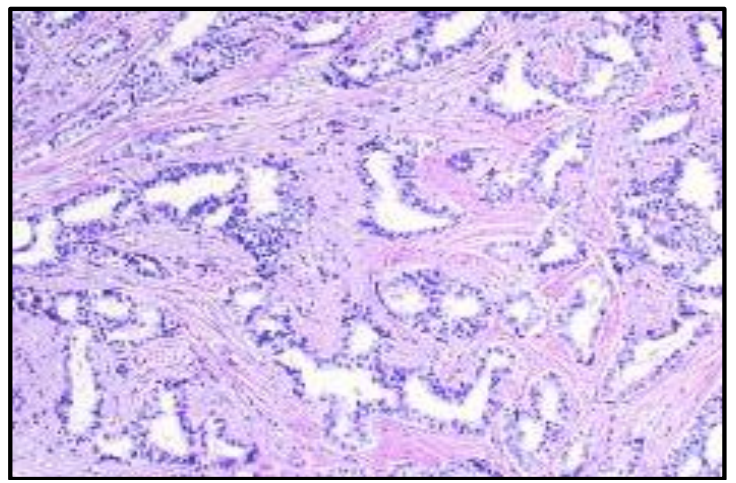

Fig. 1: Photomicrograph showing infiltrating duct carcinoma breast (H\&E x1000)

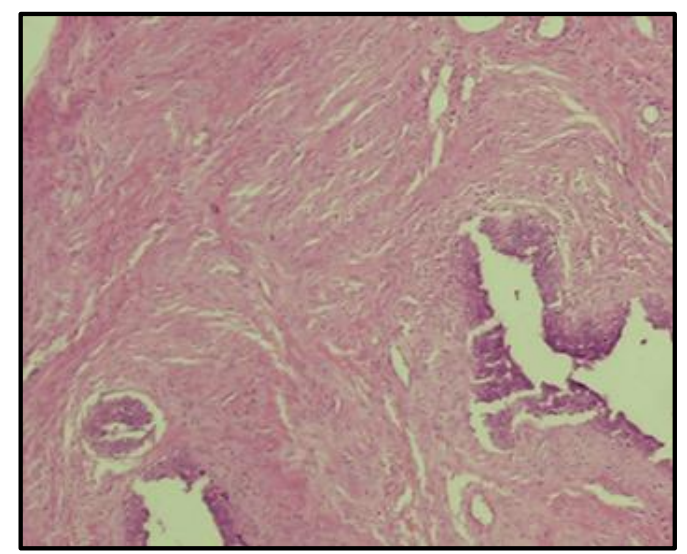

Fig. 2: Photomicrograph showing fibroadenoma breast

Table 1: Age distribution of the subjects

\begin{tabular}{|l|c|c|}
\hline Age distribution & Frequency & Percentage \\
\hline 0-15 years & 3 & 0.5 \\
\hline 16-31 years & 118 & 19.7 \\
\hline 32-46 years & 224 & 37.3 \\
\hline 47-61 years & 110 & 18.3 \\
\hline 62-76 years & 145 & 24.2 \\
\hline
\end{tabular}

Table 2: Various histological types of breast cancer according to age

\begin{tabular}{|l|c|c|c|c|c|c|c|c|}
\hline \multicolumn{2}{|c|}{ Histological types } & $\mathbf{0 - 1 5}$ & $\mathbf{1 6 - 3 1}$ & $\mathbf{3 2 - 4 6}$ & $\mathbf{4 7 - 6 1}$ & $\mathbf{6 2 - 7 6}$ & Total & Percentage \\
\hline \multirow{5}{*}{ Carcinoma } & Infiltrative ductal carcinoma & - & 72 & 111 & 61 & 73 & 317 & \\
\cline { 2 - 9 } & Ductal carcinoma in situ & - & 1 & 2 & 2 & 1 & 6 & \\
\cline { 2 - 9 } & Infiltrating lobular carcinoma & - & 40 & 78 & 31 & 61 & 210 & \\
\cline { 2 - 9 } & Lobular carcinoma in situ & - & 1 & 2 & 2 & 1 & 6 & \\
\cline { 2 - 9 } & Medullary carcinoma & - & 1 & 8 & 2 & 4 & 15 & \\
\cline { 2 - 9 } & Adenoid cystic carcinoma & - & - & - & 2 & 2 & 4 & 93 \\
\hline Sarcoma & 1 & 2 & 16 & 10 & 2 & 31 & 5.1 \\
\hline Lymphoma & 2 & 1 & 6 & - & 1 & 10 & 1.6 \\
\hline Paget's disease & - & - & 1 & - & - & 1 & 0.2 \\
\hline
\end{tabular}

\section{Discussion}

Although breast cancer is studied as a single disorder, advances in under- standing of the epidemiology, histology, and molecular base for breast cancer have indicated that it has heterogeneous nature that can be divided into various different subtypes. Increasing age is the most important risk factor for 
breast cancer. Only $2 \%$ of invasive breast carcinomas are diagnosed amongst women less than 35 years of age, ${ }^{8}$ and there is an increase in the incidence rate by a factor of 100 between $30-50$ years of age. ${ }^{9}$ Breast carcinomas amongst younger women are associated with poor overall prognosis and high recurrence rate compared to disorder amongst older women. ${ }^{10}$ This difference in survival may be due to the fact that breast cancer has lesser chances to be diagnosed at a earlier stage in young women compared to older women. ${ }^{10,11}$ However, there is also a difference in molecular and histopathological types of breast cancer occurring amongst young and elder females. ${ }^{12,13}$ In our study, majority of the cases occurred between 32-46 years of age followed by $62-76$ years. There were only 3 cases diagnosed between $0-15$ years age group. There were 118 cases between 16-31 years of age. 224 cases were diagnosed between 32-46 years of age. There were 110 cases and 145 cases diagnosed between 47-61 and 6276 years of age respectively. The average age of diagnosis of breast cancer amongst women in developing countries is lesser than in western countries. $^{14-16}$ Various risk factors like genetic, environmental, demographics, hormonal levels and dietary factors have been implicated in carcinogenesis of breast. The occurrence of early menses which is associated with early and prolonged hormonal exposure are all related to dietary habits amongst westernization of urban populations. ${ }^{17}$ There were $93 \%$ cases of carcinomas in our study. Out of these, majority $(n=317)$ were infiltrating ductal carcinomas. In 210 cases, infiltrating lobular carcinomas were confirmed histologically. There were only 4 cases of adenoid cystic carcinoma. In 15 cases medullary carcinomas were confirmed histologically. There were 6 cases each of ductal carcinoma in situ and lobular carcinoma in situ. In $5.1 \% \quad(n=31)$ sarcomas were confirmed histologically. Out of theses majority $(n=16)$ occurred between 32-46 years of age. There was only 1 case of paget's disease in our study occurring between 32-46 years of age. In $1.6 \%(\mathrm{n}=10)$ cases lymphomas were confirmed histologically. Histologically, there is prevalence of epithelial tumors in our study similar to the studies conducted previously in literature. . $^{14,15,17,18}$ These tumors have a poor pr ognosis and this has been confirmed in various literature studies. ${ }^{14-16}$

Carcinoma of the breast is a complex disease with a large intertumoral and intratumoral heterogeneity, leading to markedly variable clinical course and response to treatment modalities. ${ }^{20}$ The stage at time of diagnosis, histopathological features and hormone receptor and oncoprotein expression are other prognostic factors for breast cancer. ${ }^{21}$ Early detection of breast cancer is of substantial clinical importance, and it can be used to plan treatment modalities while tumor burden is low, and moreover, at initial stage patients are more likely to respond to adjuvant therapy. The serum concentration of tumor markers has been used to detect tumor activity. Tumor markers provide a minimally invasive cost-effective source of data valuable for monitoring disease course, determining prognosis, and helping in treatment planning. However, it is important to understand the individual test characteristics and limitations for optimal use and accurate interpretation of results. ${ }^{22}$

\section{Conclusion}

Breast cancer is the most frequently seen cancer amongst women. It is most commonly seen in elder age groups and hereditary plays an important role in its causation. The most commonly seen histological variant of breast cancer is infiltrative ductal carcinoma. Sarcomas are the second most common variant of breast cancer.

\section{References}

1. World Health Organization (WHO 2008), "The Global Burden of Disease," 2004 Update.

2. H. Rochefort and J. Rouëssé, "Breast Cancer: Incidence and Prevention," Report of a Working Group of Committee III (Cancer), 2000, p. 22.

3. Collaborative Group on Hormonal Factors in Breast Cancer (2001) Familial breast cancer: collaborative reanalysis of individual data from 52 epidemiological studies including 58,209 women with breast cancer and 101,986 women without the disease. Lancet. 358:13891399

4. Madigan MP, Ziegler RG, Benichou J, Byrne C, Hoover RN (1995) Proportion of breast cancer cases in the United States explained by well-established risk factors. $J$ Natl Cancer Inst. 87:1681-1685.

5. Hemminki K, Czene K (2002) Attributable risks of familial cancer from the Family-Cancer Database. Cancer Epidemiol Biomarkers Prev. 11:1638-1644.

6. I. Diomandé, A. F. D' Horpock, P. Heroin, M. Ette, A. Dago, F. Battesti, et al., "Evolution of Cancer in Ivory Coast," Medical Publication in Ivory Coast, Vol. 75, 1988, pp. 81-84.

7. A. Echimane, A. Ahnoux, I. Adoubi, S. Hien, K. M'Bra, A. F. D'Horpock, et al., "Cancer Incidence in Abidjan, Ivory Coast. First Results from the Cancer Registry, 1995-1997," Cancer. 2000;89(3):53-663.

8. Ries LAG, Melbert D, Krapcho M, Marriotto A, Miller BA, Feuer EJ et al (2007a) SEER cancer statistics review, 1975-2004. National Cancer Institute, Bethesda, MD.

9. Pike MC, Spicer DV, Dahmoush L, Press MF (1993) Estrogens, progestogens, normal breast proliferation, and breast cancer risk. Epidemiol Rev. 15:17-35.

10. Maggard MA, O`Connell JB, Lane KE, Liu JH, Etzioni DA, Ko CY (2003) Do young breast cancer patients have worse outcomes? J Surg Res. 113:109-113.

11. Anderson WF, Matsuno R (2006) Breast cancer heterogeneity: a mixture of at least two main types. J Natl Cancer Inst. 98:948-951.

12. Benz CC (2008) Impact of aging on the biology of breast cancer. Crit Rev Oncol Hematol. 66:65-74.

13. M. Traore, F. S. Diabate, I. Diarra, N. Mounkoro, Y. Traore, I. Tekété, et al., "Breast and Gynecologic Cancer at the Hospital from the Point G in Bamako," Medical Publication in Mali. 2004;19(2):4-9. 
14. D. Sano, R. Cissé, B. Dao, J. Lankoandé, S. S. Traore, R. B. Soudré, et al., "Breast Cancer, Diagnostic and Therapeutic Problems at the Hospital of Ouagadougou," Medical Publication in Subsaharan Africa, 1998;45(5):297-301.

15. C. R. Raharisolo Vol. olonantenaina, L. P. Rabarijiaona, C. Rajemiarimoeisoa, M. Rasendramino and R. Migliani, "Assessment of Breast Cancers Diagnosed L'institut Pasteur de Madagascar from 1995 to 2001," Archives de L'Institut Pasteur de Madagascar, 2002;68:104-108.

16. C. A. Adebamowo, S. N. Akarolo-Anthony and O. O. Temiayo, "Emerging Epidermic Breast Cancer: Evidence from Africa," Breast Cancer Research, 2010;12(1)S8.

17. A. Laplanche and E. Benhamou, "Estimated Incidence of Cancer in France," Bull Cancer, 1991;78(5):505-514.

18. E. Duarte-Franco and E. L. Franco, "Others Gynecologic Cancers: Endometrial, Ovarian, and Vaginal Cancers Vulva," BMC Women's Health, 2004;25(11):S14.

19. Makki J. Diversity of Breast Carcinoma: Histological Subtypes and Clinical Relevance. Clinical Medicine Insights Pathology. 2015;8:23-31.
20. Maffuz-Aziz A, Labastida-Almendaro S, Espejo-Fonseca A, Rodriguez-Cuevas S. Clinical and pathological features of breast cancer in a population of Mexico. Cirugía y Cirujanos (English Edition). 2017;85(3):201-7.

21. Kabel AM. Tumor markers of breast cancer: New prospectives. Journal of Oncological Sciences. 2017;3(1):5-11.

How to cite this article: Nagalikar A, Meti R. C. A retrospective cross sectional analysis of histopathological distribution of breast cancer according to age at a tertiary care teaching hospital. Indian J Pathol Oncol. 2018;5(4):646649. 